\title{
Dengue Maculopathy: Case Series
}

\author{
Lai Chan Fhun', Evelyn Tai Li Min'2,3, Hong Kee Ng1, Tun Wang Ch'ng1, Mei Fong Chong1, \\ Ahmad Tajudin Liza-Sharmini ${ }^{2,3}$ \\ ${ }^{1}$ Eye Clinic, Hospital Raja Perempuan Bainun, Ipoh, Malaysia \\ ${ }^{2}$ Department of Ophthalmology, School of Medical Sciences, Universiti Sains Malaysia, Health Campus, Kelantan, Malaysia \\ ${ }^{3}$ Eye Clinic, Hospital Universiti Sains Malaysia, Kota Bharu, Malaysia \\ Email: fhunella@hotmail.com
}

How to cite this paper: Fhun, L.C., Min, E.T.L., Ng, H.K., Ch'ng, T.W., Chong, M.F. and Liza-Sharmini, A.T. (2016) Dengue Maculopathy: Case Series. Open Journal of Ophthalmology, 6, 221-227.

http://dx.doi.org/10.4236/ojoph.2016.64031

Received: October 20, 2016

Accepted: November 11, 2016

Published: November 14, 2016

Copyright $\odot 2016$ by authors and Scientific Research Publishing Inc. This work is licensed under the Creative Commons Attribution International License (CC BY 4.0).

http://creativecommons.org/licenses/by/4.0/

\begin{abstract}
We report a case series of dengue maculopathy with different ocular manifestations, managements, visual outcomes and sequelae of patients. All three cases were diagnosed to have dengue fever. Patients presented with symptoms of central scotoma (case 1 and case 3) and blurring of vision (case 2) on Day 9 of dengue fever. Fundus examination showed intra retinal haemorrhages (case 1 and case 2) and macula thickening (case 3). Optical coherence tomography (OCT) revealed macular thickening with intra retinal fluid (case 1) and diffuse retinal thickening (case 3), while in case 2, it had irregular ellipsoid line in OCT. Fundus fluorescence angiography (FFA) revealed parafoveal vasculitis. After treatment with systemic steroids, one patient had good visual outcome (case 2), while two others had a persistent central scotoma due to macula atrophy (case 3). Although it is a self limiting disease, but the mode of treatment is variable. Treatment with corticosteroids may hasten recovery of vision and prevent permanent visual impairment.
\end{abstract}

\section{Keywords}

Dengue Fever, Maculopathy, Vasculitis

\section{Introduction}

Dengue fever is the most prevalent form of flavivirus in human which is transmitted by Aedes mosquitos [1]. It is especially endemic in the tropics and warm regions of the world [2] [3]. The disease not only affects systemic which can cause mortality. It also affects ocular as well as uveitis, maculopathy or optic neuritis [4]. Dengue maculopathy is the commonest ocular dengue diseases. The prevalence of dengue maculopathy was $10 \%$ among the hospitalized patients [5]. The commonest ophthalmic symptoms of dengue maculopathy are blurring of vision, followed by scotoma, ocular pain and me- 
tamorphopsia. The pathophysiology of dengue maculopathy is still unknown. However, many studies postulated that immune-mediated process may play an important role in pathophysiology of dengue maculopathy [6] [7]. Here we report ocular manifestation, management, visual outcome and sequelae of dengue maculopathy series cases in our center.

\section{Case Series}

\subsection{Case 1}

An 18 years old Chinese female, presented to us with right central scotoma on day 8 of dengue fever. Visual acuity of right eye was 6/24. Anterior segment and intraocular pressure (IOP) were unremarkable. Right fundus showed intra retinal haemorrhage at macula region (Figure 1(a)). Optical coherence tomography (OCT) of macula showed intraretinal and subretinal fluid (Figure 1(c)). Fundus fluoresce in angiogram (FFA) was done and showed no vasculitis seen. A diagnosis of dengue related cystoids macula

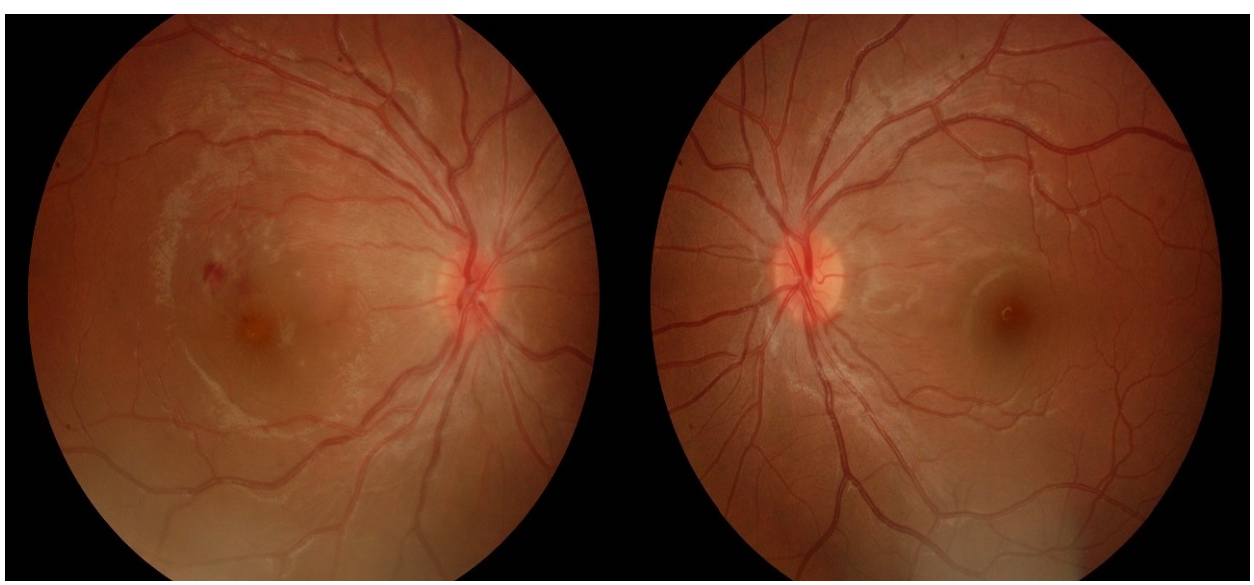

(a)

(b)

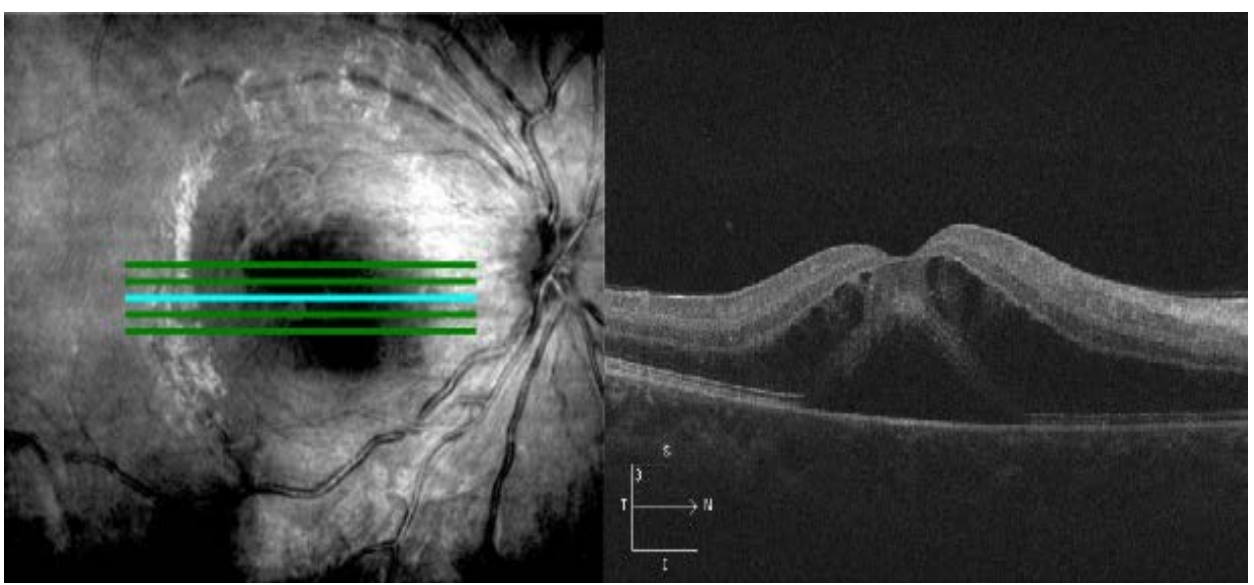

(c)

Figure 1. (a) Right eye fundus photo showing intraretinal haemorrhages at macula region; (b) Left eye fundus is normal; (c) Macula OCT of the right eye shows diffuse cystoid macula edema (Case 1). 
edema was made. Her platelet cells count was $32.2 \times 10^{9} \mathrm{~g} / \mathrm{dl}$ which was thrombocytopenia. Treatment of oral prednisolone was offered for patient, however patient refused for treatment and sought for second opinion or consultation from other ophthalmologist. However, patient was only treated conservatively. After 2 months of onset, patient's visual acuity improved to 6/12 in her right eye. However, she had persistent symptoms of central scotoma. Macula OCT of the right eye showed macula atrophy (Figure 2).

\subsection{Case 2}

A 19 years old Chinese male was referred to us for bilateral eyes blurring of vision, preceded by fever for 9 days. His visual acuity was counting fingers bilaterally. Anterior segment examination was unremarkable. The vitreous was clear. Bilateral fundus examination showed multiple dot and blot haemorrhages at the macula (Figure 3(a), Figure 3(b)). There was no macula edema. OCT macula revealed an irregular ellipsoid line and hyperrective spots at the outer retinal layer (Figure 3(c), Figure 3(d)). FFA revealed parafoveal vascuitis with an irregular parafoveal network (Figure 3(e), Figure 3(f)). Dengue fever was confirmed with positive dengue serology. Platelet cell count was $138 \times 10^{3} \mathrm{~g} / \mathrm{dl}$. Patient was diagnosed to have bilateral dengue fovealitis. In view of poor vision and retinal vasculitis, patient was treated with intravenous methylprednisolone $250 \mathrm{mg} 6$ hourly for 3 days followed by oral prednisolone $1 \mathrm{mg} / \mathrm{kg}$ ( $45 \mathrm{mg}$ daily for 11 days). Subsequently the oral prednisolone was tapered slowly over 2 months. His vision improved to $6 / 9$ within 3 weeks with complete resolution of macula haemorrhage in fundus.
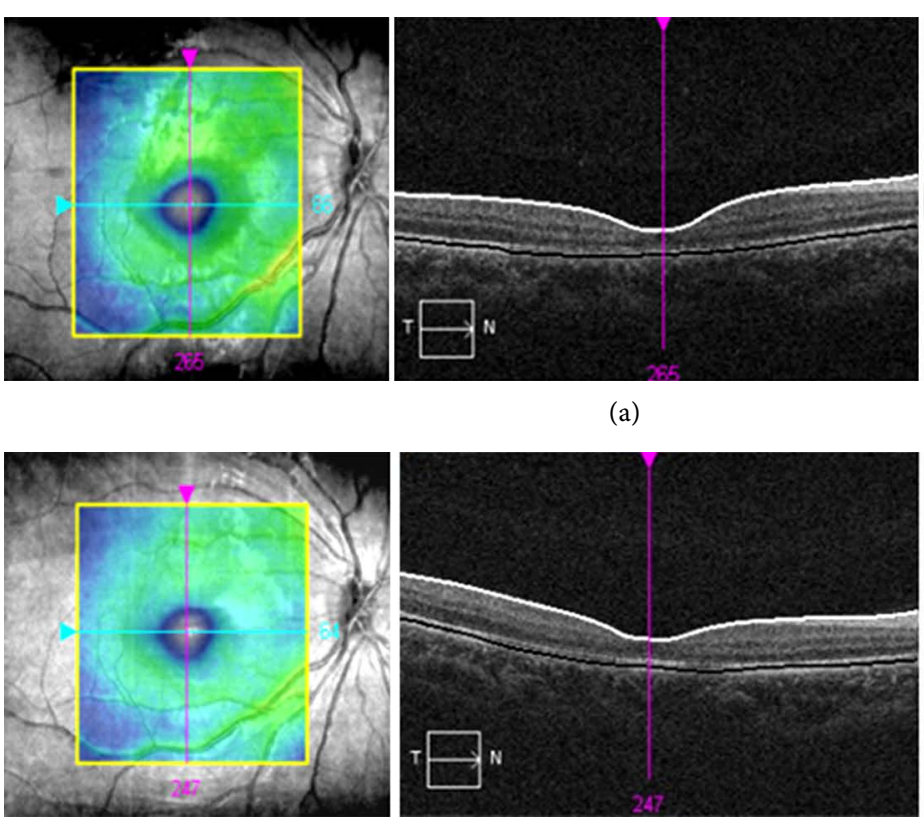

(b)

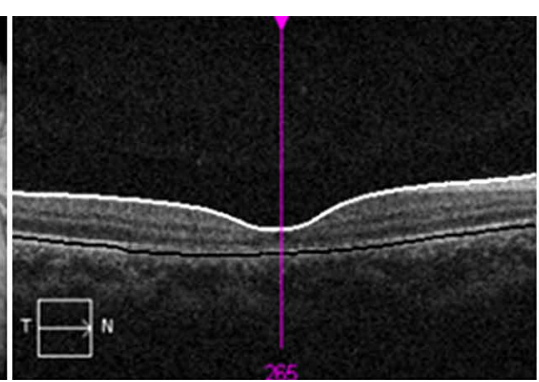

(a)

Figure 2. OCT macula of the right eye (a) 2 weeks and (b) 15 months after onset of dengue maculopathy showing right macula atrophy (Case 1). 


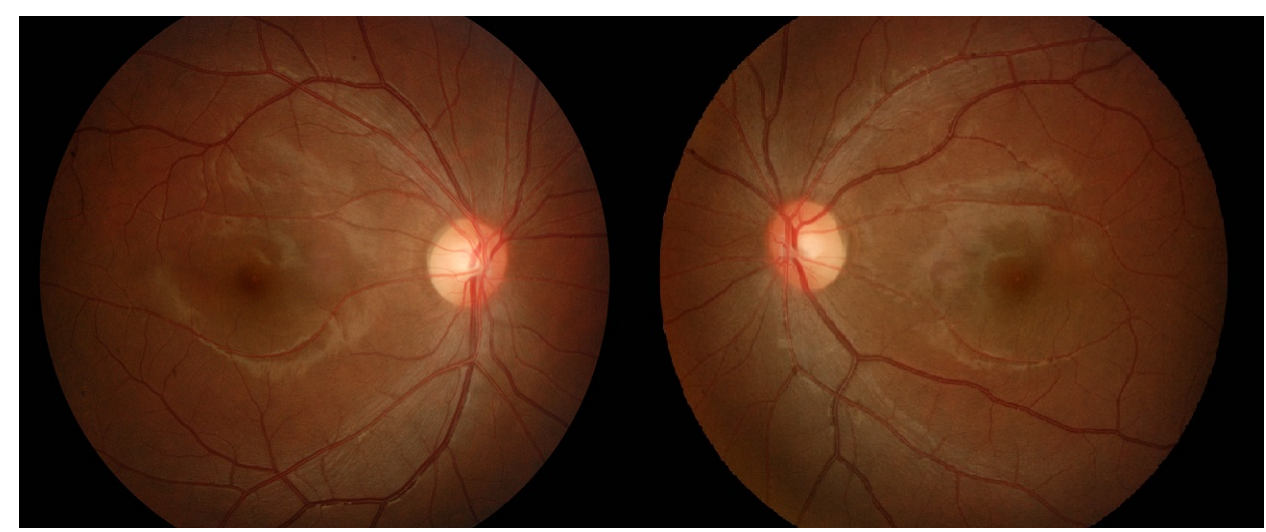

(a)

(b)

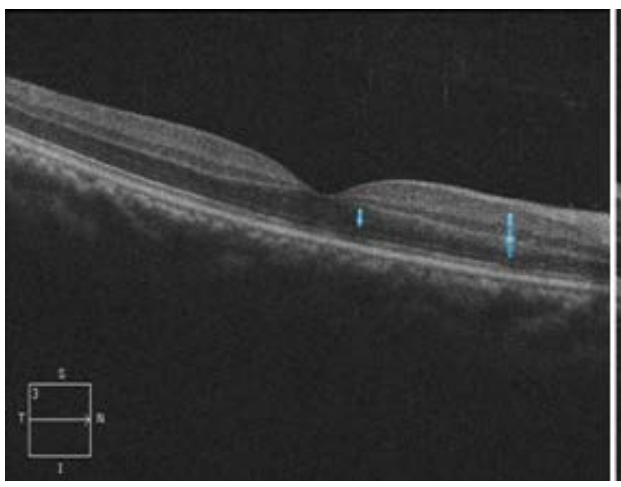

(c)

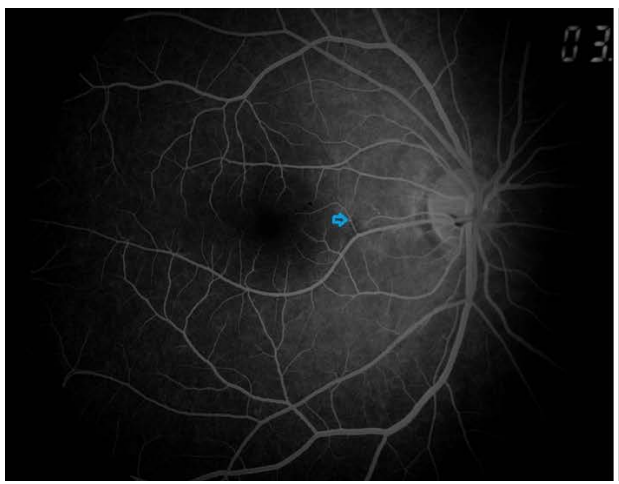

(e)

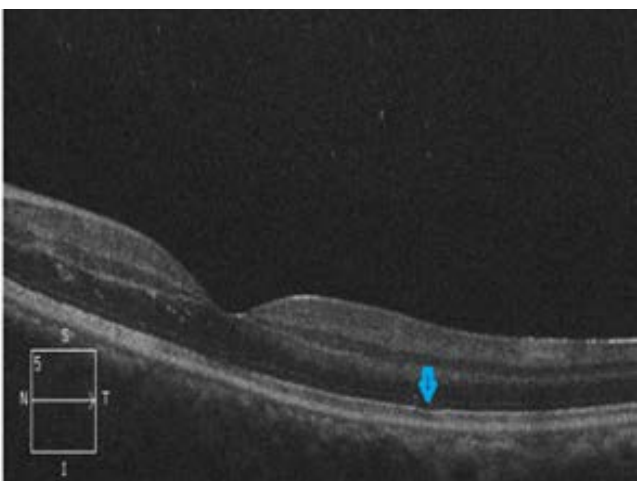

(d)

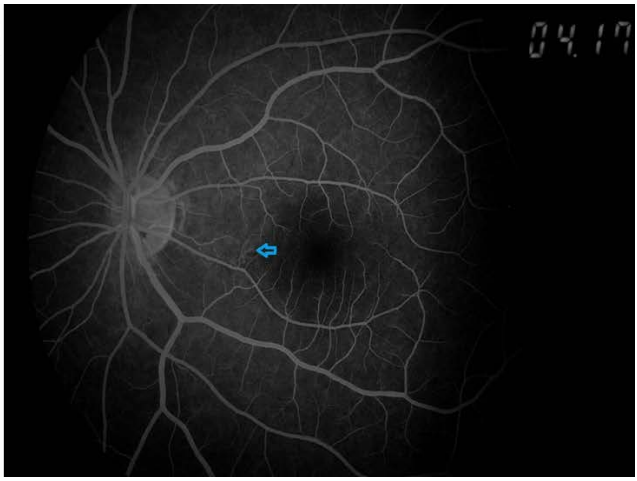

(f)

Figure 3. (a), (b) Bilateral fundus examination showed multiple dot and blot haemorrhages at the macula region. (c), (d) OCT macula of both eyes revealed irregular ellipsoid line and hyper-reflective spots at the outer layer. (e), (f) FFA of both eyes revealed parafovealvascuitis with irregular parafoveal network (Case 2).

\subsection{Case 3}

A 22 years old Chinese female, presented with left eye central blurring of vision on day 8 of dengue fever. Visual acuity was 6/6 in both eyes. Anterior segment examination was unremarkable in both eyes. Fundus examination of the left eye revealed a splinter haemorrhage temporal to optic disc with adjacent edema (Figure 4(a), Figure 4(b)). OCT of the left eye showed edema over the nasal region of macula. FFA showed no 
evidence of leakage or capillary fall out. Patient was diagnosed to have diffused retinal thickening. Her platelet cell count was $100 \times 10^{3} \mathrm{~g} / \mathrm{dl}$. Patient was treated with topical NSAIDs 3 times per day and oral prednisolone $40 \mathrm{mg}$ daily for a week then which was later tapered off. She claimed that her vision improved but the paracentral scotoma remained. Her final visual acuity was 6/6. Macula OCT showed atrophy of nerve fibre layers at the nasal part of the left macula (Figure 5).

\section{Discussion}

Dengue fever a multi-system disease, which is rare, may affect the eyes. Dengue patients with marked thrombocytopenia especially those with platelet count of less than $50 \times 10^{9}$ cells/L are more likely to develop ocular involvement which may result in vision impairment [8]. Onset of visual impairment has been observed to coincide with the nadir of serum thrombocytopenia [7]. In our series, two patients developed dengue maculopathy despite a platelet count of more than $100 \times 10^{3} \mathrm{~g} / \mathrm{dl}$.

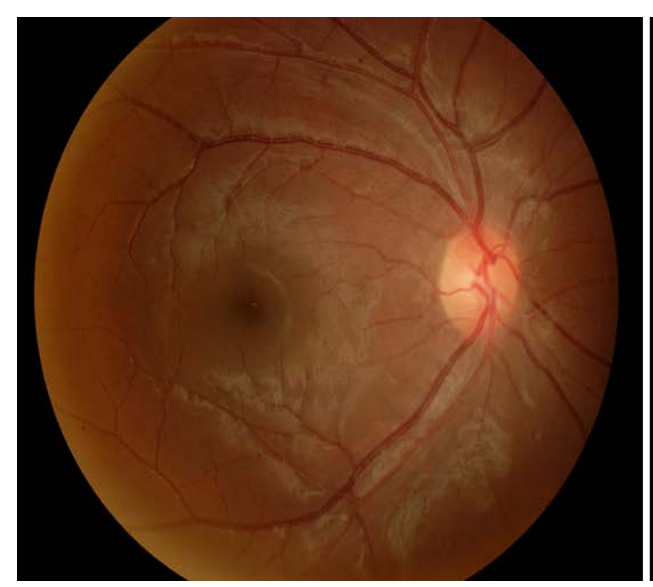

(a)

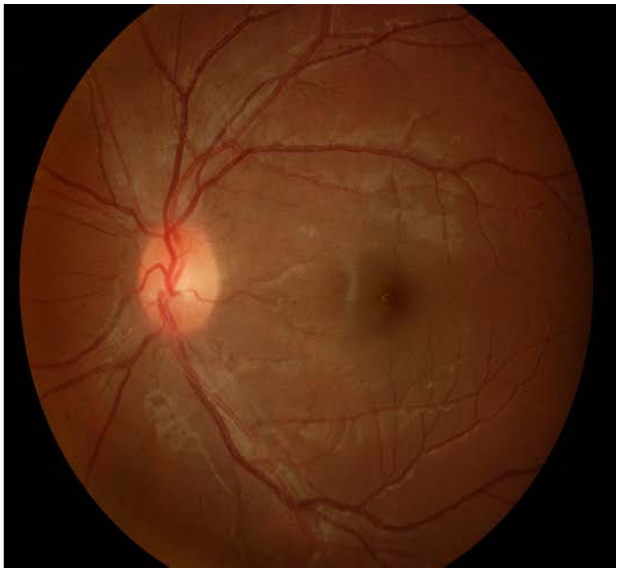

(b)

Figure 4. (a) Dot and blot haemorrhages at right macula, (b) splinter haemorrhages at left macula (Case 3).

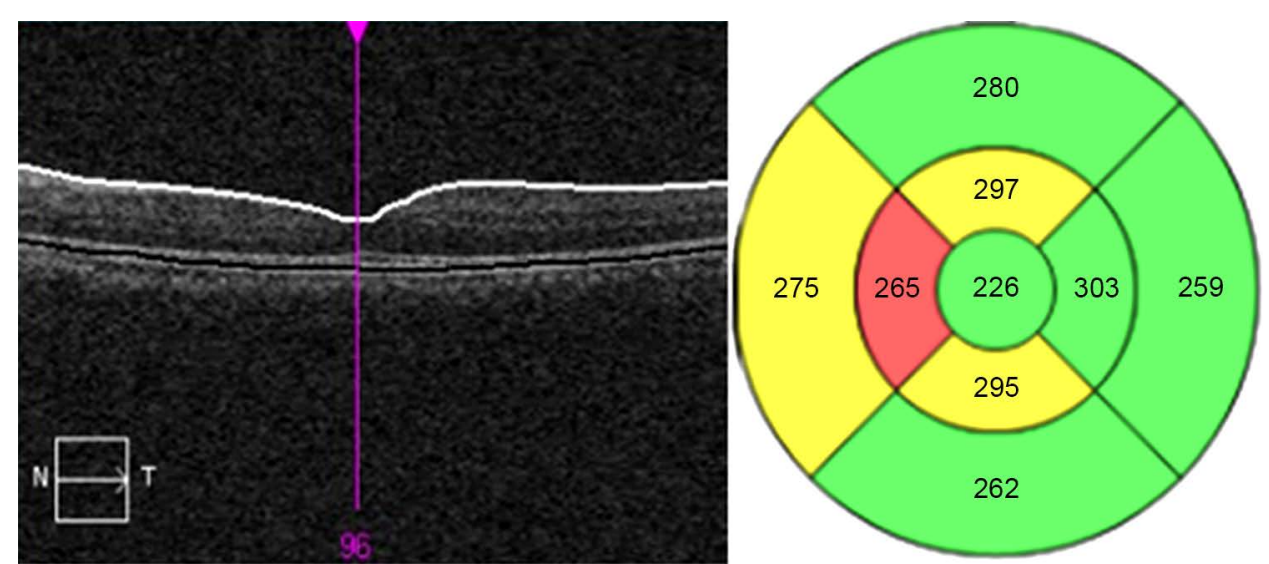

Figure 5. Left eye macula OCT after 14 months of treatment showing atrophy of the nasal part of left macula (Case 3). 
The onset of the ocular symptoms is usually 6.8 days after onset of fever [5]. The delay between the onset of dengue fever and the onset of ocular manifestations is the most probability due to immune mediated mechanisms rather than direct viral infection [9]. In our case, the onset of ocular manifestation of dengue fever was day 8 to day 9 . The main presenting symptoms are generalized blurring of vision (87\%), followed by scotoma (45\%) and floaters (1\%) [6]. In our case, 1 patient presented with generalized blurring of vision and 2 patients with central scotoma.

FFA usually demonstrates mainly vasculitis or vein occlusions [6]. Bacsal et al. (2007) reported that FFA is able to pick up venular occlusion in $25 \%$ of eyes and vascular leakage in $16 \%$ of eyes of patients with dengue related ocular signs. In case 2, patient presented with significant vision loss, however no abnormality detected on macula OCT, which is why we proceeded with FFA, which showed perifoveal vasculitis. Both OCT and FFA have their utility in identifying causes of poor visual outcome. In our third case despite good vision, the central scotoma persisted secondary to macula atrophy.

Dengue maculopathy is usually a self limiting condition. The mode of treatment includes active surveillance, anti inflammatory medication and immunosuppressive therapies [10]. Currently, there is no standardized protocol for treatment of dengue maculopathy. A retrospective study reported that 37 out of 50 patients with dengue related ocular symptoms had spontaneous resolution of clinical signs with conservative management [4]. $76 \%$ of patients had regained visual acuity of $6 / 12$ or better by 3 months.

Systemic steroids are another options; a retrospective study done in Singapore with 41 patients, which treated symptomatic patients or those with poor or deteriorating visual found that more than half of their patients achieved a visual acuity to 20/40 or better after steroid treatment. In our case, the patient was treated with intravenous methylprednisolone for 3 days followed by oral prednisolone has a visual improvement from counting fingers to 6/9 and was asymptomatic after 3 weeks.

Unfortunately, despite improvement of their visual acuity, two of our patients had a persistent central scotoma even after treatment, corresponding to macula atrophy on OCT. Teoh et al. (2006) postulated that patients may have persistent paracentral scotoma and impairment of colour vision after resolution of the illness due to a severe inflammatory insult occurring within few days. They suggested that a short course of systemic immunosupression at presentation would be beneficial. We believe that prompt treatment may reduce the visual morbidity. However, more randomized clinical trials are needed to determine the best form and timing of treatment of patients with dengue maculopathy

\section{Conclusion}

Dengue related eye disease is an uncommon cause of ocular morbidity. It may result in permanent visual impairment as macula atrophy after resolution of macula edema. FFA should be done to look for evidence of vasculitis. However, further randomized clinical studies are needed to confirm the validity. Even though it is a self limiting disease, the 
treatment may fasten the recovery of vision, and it might have residual of macula atrophy. Therefore, early diagnosis and treatment needed to prevent permanent visual impairment.

\section{References}

[1] Kuhn, R.J., Zhang, W., Rossmann, M.G., Pletnev, S.V., Corver, J., Lenches, E., Jones, C.T., Mukhopadhyay, S., Chipman, P.R., Strauss, E.G., Baker, T.S. and Strauss, J.H. (2002) Structure of Dengue Virus. Cell, 108, 717-725. http://dx.doi.org/10.1016/S0092-8674(02)00660-8

[2] Halstead, S.B. (1966) Mosquito-Borne Haemorrhagic Fevers of South and South-East Asia. Bulletin of the World Health Organization, 35, 3-15.

[3] Halstead, S.B. (1990) Global Epidemiology of Dengue Hemorrhagic Fever. The Southeast Asian Journal of Tropical Medicine and Public Health, 21, 636-641.

[4] Teoh, S.C.B., Chana, D.P.L., Nah, G.K.M., Rajagopalana, R., Laudea, A., Angd, B.S.P., Barkhame, T., Cheeb, C.K.L., Lima, T.H. and Goha, K.Y. (2006) A Re-Look at Ocular Complications in Dengue Fever and Dengue Haemorrhagic Fever. Dengue Bulletin, 30, 183-193.

[5] Su, D.H.W., Bacsal, K., Chee, S.P., Flores, J.V.P., Lim, W.K., Cheng, B.C.L. and Jap, A.H.E. (2007) Prevalence of Dengue Maculopathy in Patients Hospitalized for Dengue Fever. Ophthalmology, 114, 1743-1744. http://dx.doi.org/10.1016/j.ophtha.2007.03.054

[6] Bacsal, K., Chee, S., Cheng, C. and Flores, J. (2007) Dengue-Associated Maculopathy. Archives of Ophthalmology, 125, 501-510. http://dx.doi.org/10.1001/archopht.125.4.501

[7] Chan, D.P.L., Teoh, S.C.B., Tan, C.S.H., Nah, G.K.M., Rajagopalan, R., Prabhakaragupta, M.K., Chee, C.K.L., Lim, T.H. and Goh, K.Y. (2006) Ophthalmic Complications of Dengue. Emerging Infectious Diseases, 12, 285-289. http://dx.doi.org/10.3201/eid1202.050274

[8] Kumar, V., Kataria, R. and Mehta, V.S. (2011) Dengue Hemorrhagic Fever: A Rare Cause of Pituitary Tumor Hemorrhage and Reversible Vision Loss. Indian Journal of Ophthalmology, 59, 311-312. http://dx.doi.org/10.4103/0301-4738.82002

[9] Lim, W.K., Mathur, R., Koh, A., Yeoh, R. and Chee, S.P. (2004) Ocular Manifestations of Dengue Fever. Ophthalmology, 111, 2057-2064.

http://dx.doi.org/10.1016/j.ophtha.2004.03.038

[10] Ng, A.W. and Teoh, S.C. (2015) Dengue Eye Disease. Survey of Ophthalmology, 60, 106114. http://dx.doi.org/10.1016/j.survophthal.2014.07.003 
Submit or recommend next manuscript to SCIRP and we will provide best service for you:

Accepting pre-submission inquiries through Email, Facebook, LinkedIn, Twitter, etc. A wide selection of journals (inclusive of 9 subjects, more than 200 journals)

Providing 24-hour high-quality service

User-friendly online submission system

Fair and swift peer-review system

Efficient typesetting and proofreading procedure

Display of the result of downloads and visits, as well as the number of cited articles

Maximum dissemination of your research work

Submit your manuscript at: http://papersubmission.scirp.org/

Or contact ojoph@scirp.org 